\title{
Budbreak induction in kiwifruit vines cultivated in an organic system by the biological method of single node cutting
}

\author{
Rodrigo Fernandes dos Santos ${ }^{1}$ (D), Léo Omar Duarte Marques ${ }^{1^{*}}$ (D), \\ Paulo Mello-Farias ${ }^{1}$ iD, Carlos Roberto Martins ${ }^{2}$ (D) Luis Henrique Konzen ${ }^{1}$ (D), \\ Ivan Ricardo Carvalho ${ }^{3}$ (D), Marcelo Barbosa Malgarim ${ }^{1}$ (D) \\ 1.Universidade Federal de Pelotas - Faculdade de Agronomia Eliseu Maciel - Departamento de Fitotecnia - Pelotas (RS), Brazil. \\ 2.Empresa Brasileira de Pesquisa Agropecuária - Centro de Pesquisas Agropecuárias do Clima Temperado - Pelotas (RS), Brazil. \\ 3.Universidade Regional do Noroeste do Estado do Rio Grande do Sul - Departamento de Estudos Agrários - ljuí (RS), Brazil.
}

\begin{abstract}
Kiwifruit vines are an alternative approach to diversify Brazilian fruit farming because of the low supply and increase in the demand for their fruits. Hydrogenated cyanamide, which is the most common rest-breaking agent, is highly toxic and its use is not allowed in organic production systems. This study aimed at evaluating the efficiency of alternative rest-breaking agents in kiwifruit vines by using the biological method of single node cutting. Twigs of the cultivar Bruno were collected in an organic orchard in Pelotas, a city located in Rio Grande do Sul state, Brazil. Seven-centimeter-long cuts with a single shoot at the ends were segmented. Cuttings were placed on plastic trays with phenolic foam and soaked in water, at $85 \%$ relative humidity on average, and kept in bio-oxygen demand (BOD) incubators at $25 \pm 1{ }^{\circ} \mathrm{C}$ and a 16-h photoperiod. Budbreak was evaluated in 2-day and 3-day intervals. The experiment was conducted in a completely randomized design with ten treatments and three replications of ten sampling units each. The following variables were analyzed: average budbreak time (ABT), final budbreak rate (FBR), vigorous budbreak rate (VBR), velocity of budbreak (VB), percentage of open buds (POB) and dormancy index (DI). The rest-breaking agent garlic extract (GE) $10 \%+$ mineral oil (MO) $2 \%$ was the most efficient one in budbreak induction in both production cycles. Thus, this dose is recommended for budbreak induction in kiwifruit vines grown in an organic system.
\end{abstract}

Key words: Actinidia deliciosa, sustainability, ecophysiology, adaptation, mild winter.

\author{
Received: \\ Aug. 19, 2019 \\ Accepted: \\ Feb. 3, 2020 \\ Section Editor: \\ Cláudia Sales Marinho \\ ${ }^{*}$ Correspondence author: \\ leodmq@hotmail.com
}

\section{INTRODUCTION}

Kiwifruit has had high demand in the Brazilian domestic market due to its therapeutic properties, such as its high content of vitamin C (Soqueta et al. 2016). The kiwi tree is a temperate climate perennial plant, and it has a dormancy mechanism, which can be simply explained as the temporal absence of growth during low temperature periods, working as an adaptation mechanism (Hoeberichts et al. 2017).

Every cultivar requires a certain number of cold hours below $7.2^{\circ} \mathrm{C}$ to overcome dormancy, according to the model of dormancy evaluation proposed by Weinberger (1950). However, when chilling requirement is not totally supplied, the application of hydrogenated cyanamide is recommended at concentrations that range from 1 to $3 \%$, depending on the cultivar, from three to five weeks before budbreak. However, there is a major problem related to the high toxicity of the commercialized product which has hydrogenated cyanamide in its formula. It is highly toxic to the environment and potentially carcinogenic to humans, and its use is prohibited in sustainable production systems such as the organic one (Ímrak et al. 2016). 
Dependence on hydrogenated cyanamide is a problem that affects all temperate fruit trees. Perussi et al. (2010) studied the effect of garlic extract (GE) on dormancy break in apple trees (Malus domestica) and carried out an experiment in which one of the treatments was hydrogenated cyanamide. They concluded that the rest-breaking agents that led to the highest budbreak average were Bioalho (GE, Natural Rural S.A.) mixed with mineral oil (MO) and natural garlic (a product which results from garlic extraction by cold pressing) mixed with MO.

The empirical method, which consists in adding cold hours below $7.2^{\circ} \mathrm{C}$, proposed by Weinberger (1950), is the most common method to evaluate dormancy and dormancy break due to its easiness regarding calculation and understanding, rather than its precision (Hawerroth et al. 2010). There are biological methods of dormancy evaluation which employ plant material in their tests; as a result, they increase precision of studies of dormancy, since they use phenology as the basis for the evaluation of dormancy evolution and break (Hawerroth et al. 2010).

The most common biological method which has been applied to the study of dormancy is the single node cutting test (Champagnat 1983; Hawerroth et al. 2010). When cuttings with an only bud formed from stems are used, the effect of correlative inhibition is eliminated and buds can develop all their potential (Champagnat 1983). Average budbreak time is analyzed, since it is an indicator of dormancy depth. This test is appropriate to analyze a large number of variables, including the efficiency shown by products to overcome dormancy (Citadin et al. 2002).

Studies have proven that alternative rest-breaking agents are efficient in temperate fruit trees, such as apple trees. Thus, some agent may lead to good results of budbreak induction in kiwifruit vines. This study aimed at evaluating the effect of alternative compounds on budbreak induction and dormancy of kiwifruit vine cuttings by using the biological method of single node cutting in a controlled environment.

\section{MATERIAL AND METHODS}

The experiment was carried out in Pelotas, a city located in Rio Grande do Sul state (RS), Brazil, in 2016 and 2017, with twigs of kiwifruit vines of cultivar Bruno. They were collected in a commercial orchard which has followed the principles of organic production implemented in 2007 in Cascata, Pelotas, RS ( $31^{\circ} 58^{\prime} 30^{\prime \prime}$ S, 52 $51^{\circ} 50^{\prime \prime} \mathrm{W}$ and $181 \mathrm{~m}$ altitude). Twigs were one year old, 50 -cm long, on average, intact, healthy, with homogeneous diameters, in an oblique position in the plant.

Treatments consisted of different concentrations of GE, with or without any combination of Assist (750 mL.L-1 MO, Basf S.A.), spring onion extract (SOE) at $10 \%$ with or without combination of Assist (750 mL.L-1 MO, Basf S.A.) and MO at $2 \%$.

Samples of common white garlic (Allium sativum L.) and spring onion (Allium fistolusum L.) were provided by a farmer who raises organic vegetables in Pelotas, RS. They were harvested three days before the experiment and kept in a dry, airy and shady place at room temperature. Garlic extract resulted from peeled cloves of common white garlic (Allium sativum L.), which were triturated by a juice extractor, similar to a kitchen centrifuge, filtered through a cloth strainer and stored in containers wrapped in tin foil up to the application, right after the preparation; yield was in the ratio 3:1 (weight:volume). Spring onion extract resulted from maceration of spring onion (Allium fistolusum L.) leaves by the same methodology used for formulating GE.

In order to evaluate cold availability in every cycle, the number of cold hours that occurred in both studies were calculated. This study used climate data provided by the meteorological station at the Embrapa Clima Temperado, located in Cascata, Pelotas, RS. The number of cold hours was registered by the model proposed by Weinberger (1950), who considers cold hours below $7.2^{\circ} \mathrm{C}$.

Seven-centimeter-long cuttings were segmented by a digital caliper; buds located between the 4th and the 14th nodes on the collected twigs, counting from their bases, were used. Only one bud was kept on the upper parts of the cuttings, which were cut $1 \mathrm{~cm}$ above the intact bud. The upper part of every cutting was paraffined to prevent it from losing humidity. Twig segments were placed on plastic trays with phenolic foam and soaked in water; it kept the bases of the cuttings soaked throughout the experiment. Average relative humidity was kept at $85 \pm 1 \%$ in the whole experiment.

Treatments consisted of the following solutions: treatment 1, garlic extract (GE 5\%); treatment 2, garlic extract (GE 10\%); treatment 3, garlic extract 15\% (GE 15\%); treatment 4 mineral oil 2\% (MO 2\%); treatment 5 garlic extract 5\% + 
mineral oil 2\% (GE 5\% + MO 2\%); treatment 6 garlic extract 10\% + mineral oil 2\% (GE 10\% + MO 2\%); treatment 7 garlic extract 15\% + mineral oil 2\% (GE 15\% + MO 2\%); treatment 8 spring onion extract 10\% (SOE 10\%); treatment 9 spring onion extract 10\% + mineral oil 2\% (SOE 10\% + MO 2\%); and treatment 10 control treatment, with no application (NA). All applications were carried out with a sprayer up to "dripping", in every treatment and their parcels.

Dormancy evaluation was conducted by the biological test in bio-oxygen demand (BOD) incubators at $25 \pm 1{ }^{\circ} \mathrm{C}$ and a 16-hour photoperiod. The experiment had a completely randomized design. Three replicates were used per treatment; each one was composed of ten sample units and every cutting represented a sample unit.

Individual evaluation of budbreaks of every cutting was carried out every two or three days for 23 days in the 2016 experiment and for 27 days in the 2017 experiment. Buds meant the stage of "green tip" (GT) and "open bud" (OB) in agreement with the BBCH scale for kiwifruit vines, in the phenological stages illustrated by Salinero (2009).

Based on these stages, the following calculations were carried out: average budbreak time (ABT), which represents the average number of days spent between the experiment implementation and detection of the GT stage; final budbreak rate (FBR), which represents the percentage of cuttings with buds that reached GT; vigorous budbreak rate (VBR), which represents the percentage of cuttings with buds that were in the GT stage and evolved to the OB stage [VBR $=$ (\% of cuttings with buds in the OB stage $\times 100 / F B R$; velocity of budbreak $(\mathrm{VB})$, which evaluates budbreak in function of budbreak time, given by the equation $\mathrm{VB}=\Sigma(\mathrm{ni} / \mathrm{ti})$ (buds/day), where $\mathrm{ni}=$ number of buds that reached the GT stage at time "i" and ti = time after the test implementation ( $\mathrm{i}=1 \rightarrow 23$ or 27 ). The dormancy index (DI) was determined by the general formula developed by Carvalho and Silva (2010): DI = ABT (k.FBR + w.VB + VBR $)^{-1}$. This index is directly proportional to the average budbreak time (ABT) and inversely proportional to the final budbreak rate (FBR), to the velocity of budbreak (VB) and to the vigorous budbreak rate (VBR) and enables dormancy intensity to be classified into five different levels (Carvalho and Biasi 2012).

Both years under evaluation were separately analyzed. Averages of test results of every variable were submitted to the analysis of variance. Effects of treatments were evaluated by the F-test; when they were significant, averages were compared by the Tukey's test $(\mathrm{p} \leq 0.05)$. Statistical analyses were carried out by the RStudio program, version 3.3.1 (2016).

\section{RESULTS AND DISCUSSION}

In 2016, 348 cold hours were recorded, while 198 cold hours were recorded in 2017, in agreement with the model of cold hours proposed by Weinberger (1950), who considers cold hours below $7.2^{\circ} \mathrm{C}$. Difference in accumulation of cold in both years when experiments were carried out influenced budbreak behavior.

In the experiment conducted in 2016 (Table 1), rest-breaking agents led to changes in the dynamics of budbreak, i. e., in the final budbreak rate (FBR), the percentage of open buds (OB), the average budbreak time (ABT), the dormancy index (DI) and the velocity of budbreak (VB). Velocity of budbreak (Table 2) was higher in treatments GE 10\% + MO 2\%, GE $5 \%+\mathrm{MO} 2 \%$ and GE $10 \%$ than in the other treatments. Differences were significant and showed that these agents trigger budbreak, a fact that leads to early budbreak of kiwifruit cuttings. The treatment GE 15\% + MO 2\% exhibited the worst results and differed from the control significantly. This result infers that buds may undergo phytotoxicity, due to the high concentration of garlic associated with mineral oil, and suggests that the application of concentrations of garlic extract close to $15 \%$ should be avoided.

Carvalho et al. (2016), when researching sprouting induction in American vine species, found that high dosages of garlic extract, regardless of whether or not associated with mineral oil, causes phytotoxicity reducing by half the percentage of sprouting. These authors observed that $20 \%$ of garlic extract caused phytotoxicity in the vine buds, corroborating to the importance of studying the optimal dosage for each crop, as higher dosages do not mean better sprouts.

According to Leonel et al. (2015), the ideal dosage for a producer to break dormancy is when the lowest inductor concentration provides the best budding rates, as the use of lower concentrations is an indication of reduced product costs. In another words, it is not necessary to use high levels of concentration in the garlic extract application to obtain good results, indicating higher product efficiency to induce sprouting. 
Table 1. Final budbreak rate (FBR), percentage of open buds (POB), average budbreak time (ABT), vigorous budbreak rate (VBR) and dormancy index (DI) in single node cuttings of 'Bruno' kiwifruit vines submitted to different rest-breaking agents in two years (2016 and 2017).

\begin{tabular}{|c|c|c|c|c|c|}
\hline \multicolumn{6}{|c|}{2016} \\
\hline Treatment & FBR (\%) & POB (\%) & ABT (days) & VBR (\%) & DI \\
\hline GE $10 \%+$ MO $2 \%$ & $76.67 a$ & $53.33 a$ & $8.97 a b$ & 68.78 & $0.01 b$ \\
\hline MO $2 \%$ & $66.67 a b$ & $50.00 \mathrm{ab}$ & $6.84 a b$ & 70.74 & $0.01 b$ \\
\hline GE $10 \%$ & $56.67 a b$ & $50.00 \mathrm{ab}$ & $5.81 b$ & 88.89 & $0.01 b$ \\
\hline GE $5 \%+M O 2 \%$ & $66.67 a b$ & $36.67 b$ & $8.05 a b$ & 58.86 & $0.01 b$ \\
\hline SOE $10 \%+$ MO $2 \%$ & $66.67 a b$ & $33.33 b$ & $9.60 a b$ & 52.26 & $0.01 b$ \\
\hline GE 5\% & $50.00 \mathrm{ab}$ & $33.33 b$ & $6.98 \mathrm{ab}$ & 71.11 & $0.01 b$ \\
\hline GE $15 \%$ & $56.67 a b$ & $33.33 b$ & $7.88 a b$ & 55.24 & $0.01 \mathrm{~b}$ \\
\hline No application & $46.67 \mathrm{ab}$ & $26.67 b$ & $10.6 a$ & 58.33 & $0.02 a b$ \\
\hline SOE $10 \%$ & $33.33 b$ & $20.00 \mathrm{~b}$ & $8.97 \mathrm{ab}$ & 58.33 & $0.02 a b$ \\
\hline GE $15 \%+$ MO $2 \%$ & $30.00 \mathrm{~b}$ & $16.67 c$ & $11.2 \mathrm{a}$ & 61.11 & $0.03 a$ \\
\hline AVERAGE & 55.00 & 35.33 & 8.50 & $64.37^{\text {ns }}$ & 0.0194 \\
\hline \multicolumn{6}{|c|}{2017} \\
\hline Treatment & FBR (\%) & $\mathrm{POB}(\%)$ & ABT (days) & VBR (\%) & $\mathrm{DI}$ \\
\hline GE $10 \%+$ MO $2 \%$ & 53.33 & $46.67 a$ & 9.12 & 86.90 & 0.01 \\
\hline MO 2\% & 50.00 & $43.33 \mathrm{a}$ & 10.62 & 86.11 & 0.02 \\
\hline GE $10 \%$ & 46.67 & $36.67 b$ & 11.00 & 77.78 & 0.02 \\
\hline GE 5\% + MO 2\% & 46.67 & $40.00 \mathrm{ab}$ & 11.02 & 85.00 & 0.02 \\
\hline SOE $10 \%+$ MO $2 \%$ & 46.67 & $36.67 b$ & 11.60 & 78.33 & 0.02 \\
\hline GE 5\% & 43.33 & $33.33 b$ & 11.68 & 76.67 & 0.02 \\
\hline GE $15 \%$ & 40.00 & $33.33 b$ & 10.91 & 85.00 & 0.02 \\
\hline No application & 40.00 & $26.67 b$ & 11.64 & 68.33 & 0.03 \\
\hline SOE $10 \%$ & 36.67 & $30.00 \mathrm{~b}$ & 11.31 & 80.56 & 0.03 \\
\hline GE $15 \%+$ MO 2\% & 30.00 & $26.67 b$ & 10.33 & 88.89 & 0.03 \\
\hline AVERAGE & $43.33^{\text {ns }}$ & 35.33 & $10.9^{\text {ns }}$ & $81.36^{\text {ns }}$ & $0.02^{\text {ns }}$ \\
\hline
\end{tabular}

*Averages followed by different letters in the columns differ by the Tukey’s test at $5 \%$ significance. ${ }^{* *} n s:$ nonsignificant by the F-test.

Table 2. Distribution of the number of buds per day and velocity of budbreak (VB) (buds·day-1) in cuttings of 'Bruno' kiwifruit vines collected in 2016.

\begin{tabular}{|c|c|c|c|c|c|c|c|c|c|c|}
\hline \multicolumn{11}{|c|}{2016} \\
\hline \multirow{2}{*}{ Treatment } & \multicolumn{9}{|c|}{ Days after implementation } & \multirow[t]{2}{*}{ VB (buds $\cdot$ day $^{-1}$} \\
\hline & 2 & 4 & 6 & 9 & 12 & 15 & 17 & 20 & 23 & \\
\hline GE $10 \%+$ MO $2 \%$ & 1 & 9 & 5 & 1 & 0 & 3 & 0 & 2 & 2 & $1.3605 \mathrm{a}$ \\
\hline GE $10 \%$ & 1 & 11 & 3 & 0 & 0 & 0 & 2 & 0 & 0 & $1.2892 \mathrm{a}$ \\
\hline GE $5 \%+M O 2 \%$ & 4 & 3 & 8 & 0 & 0 & 1 & 1 & 2 & 1 & $1.4508 \mathrm{a}$ \\
\hline MO 2\% & 0 & 1 & 13 & 0 & 3 & 0 & 1 & 1 & 1 & $0.9397 a b$ \\
\hline SOE $10 \%+$ MO $2 \%$ & 0 & 0 & 12 & 0 & 2 & 1 & 4 & 1 & 0 & $0.8395 \mathrm{ab}$ \\
\hline GE 5\% & 1 & 7 & 2 & 1 & 2 & 1 & 1 & 0 & 0 & $0.9955 a b$ \\
\hline GE $15 \%$ & 1 & 7 & 3 & 1 & 2 & 1 & 1 & 1 & 0 & $1.0678 a b$ \\
\hline No application & 0 & 1 & 5 & 1 & 2 & 3 & 1 & 1 & 0 & $0.5566 \mathrm{ab}$ \\
\hline SOE $10 \%$ & 1 & 2 & 2 & 0 & 3 & 1 & 1 & 0 & 0 & $0.5696 a b$ \\
\hline GE $15 \%+$ MO $2 \%$ & 0 & 0 & 5 & 0 & 0 & 1 & 2 & 0 & 1 & $0.3537 b$ \\
\hline
\end{tabular}

*Averages followed by different letters in the columns differ by the Tukey's test at $5 \%$ significance. 
The variable average budbreak time also exhibited differences among treatments under investigation in the 2016 experiment (Table 1). The application of GE 15\% + MO 2\% showed the highest average budbreak time by comparison with the other treatments; it did not differ from the treatment with no application, i. e., the average number of days needed for budbreak was higher in this treatment by comparison with the others. The application of GE $10 \%$ was found to be the one that had the lowest value of ABT (Table 1). This treatment decreased the time between the experiment implementation and the GT stage in buds of kiwifruit cuttings.

The variable final budbreak rate (Table 1) was found to exhibit the best result when GE 10\% + MO 2\% was applied; it led to about $76 \%$ of budbreak. Both treatments SOE 10\% e GE 15\% + MO 2\% had the worst averages by comparison with the other treatments, within this variable.

Dormancy index (Table 1) was higher when GE 15\% + MO 2\% was applied. Since it was even higher than the control (with no application), it may be inferred that this treatment did not lead kiwifruit cuttings to overcome endodormancy. The other treatments changed the dormancy index, thus suggesting that they made kiwifruit vine buds leave the endodormancy phase. Dormancy, when divided into three phases (para-, endo-, and ecodormancy), has the endodormancy as crucial one, because the cold accumulation during autumn/winter period is fundamental for the plant physiological processes during this phase. However, the use of sprouting inductors can serve as a supplement (El Yaacoubi et al. 2016). In this research, it can be observed that it is very important to choose the correct bud inductor and its concentration, because not all inductors and not all tested concentrations could complement the lack of coldness and consequently induce a good sprouting.

The variable $\mathrm{OB}$ (\% of open buds) reached the best results in the treatment GE $10 \%+\mathrm{MO} 2 \%$, followed by treatments $\mathrm{MO}$ $2 \%$ and GE $10 \%$ (Table 1). The vigorous budbreak rate (VBR) did not undergo any changes as the result of rest-breaking agents.

Regarding the distribution of the numbers of buds that sprouted in the 2016 experiment (Table 2), budbreak took place in some treatments on the second day after the experiment implementation, while the control had buds from the fourth day on and, effectively, from the sixth day on, a fact that infers that rest-breaking agents applied to them hastened budbreak. Treatments with GE 10\% + MO 2\%, GE 5\% +MO 2\%, GE 10\% and MO 2\% induced budbreak in about 15 cuttings six days after the experiment implementation. These were the best treatments.

Abou-Zaid and Badawy (2018), when studying the application of five different sprouting inductors in grapevines, found that garlic extract showed similar results to hydrogenated cyanamide at sprouting speed, which was the products that induced bud sprouting faster. Leonel et al. (2015) also verified the speed of garlic extract in inducing sprouting in fig buds, and the early sprouting coincided with an early fig harvest. These data associated with the present research point to the fact that garlic extract, if used in the proper concentration, has the ability to induce early sprouting. Table 3 shows that, in general, budbreak took place later in the 2017 experiment, i.e., it occurred from the 7 th evaluation day on. Velocity of budbreak was higher when GE 10\% + MO 2\% was applied, thus, inferring that garlic extract had the highest effect on budbreak of kiwifruit cuttings in both years.

Budbreak was uneven in the experiment of 2017 compared to that of 2016 , when budbreak was more concentrated. The more uneven and lower budbreak that was observed in the 2017 experiment may have happened due to the low accumulation of cold hours. According to Hawerroth et al. (2010), when the number of cold hours in winter is much lower than the need of certain temperate fruit trees, a phenomenon called "erraticism" occurs. It means that budbreak and blooming are uneven and insufficient, a fact that was observed in the high lack of uniformity at the budbreak period, as well as low budbreak in the 2017 experiment, in which accumulation of cold was lower, affecting the phenology of kiwifruit vines directly.

Results of budbreak were found to be lower in the 2017 experiment than the ones reached in the 2016 experiment. Difference in accumulation of cold hours between both years under study show the influence of cold on the efficiency of rest-breaking agents. According to Faust et al. (1997), the explanation is that rest-breaking agents are capable of replacing just part of the cold requirement of a cultivar, thus, serving as complements.

The issue brought up by Faust et al. (1997) explains the low results found in the 2017 experiment, since the accumulation of cold was much lower than the required by the cultivar. According to Silveira et al. (2012), the cultivar Bruno needs a cold period that ranges from 300 to $400 \mathrm{~h}$ below $7.2^{\circ} \mathrm{C}$ to reach good budbreak. Therefore, 198 cold hours in the 2017 hibernal period affected budbreak of 'Bruno' kiwifruit vines negatively. 
Table 3. Distribution of the number of buds per day and velocity of budbreak (VB) (buds·day ${ }^{-1}$ ) in cuttings of 'Bruno' kiwifruit vines collected in 2017 .

\begin{tabular}{|c|c|c|c|c|c|c|c|c|c|c|c|c|c|}
\hline \multirow{2}{*}{ Treatment } & \multicolumn{12}{|c|}{ Days after implementation } & \multirow{2}{*}{ VB (buds $\cdot$ day $^{-1}$ ) } \\
\hline & 2 & 5 & 7 & 9 & 12 & 14 & 16 & 19 & 21 & 23 & 26 & 28 & \\
\hline GE $10 \%+$ MO $2 \%$ & 0 & 0 & 7 & 5 & 3 & 0 & 0 & 1 & 0 & 0 & 0 & 0 & $0.6194 \mathrm{a}$ \\
\hline $\mathrm{MO} 2 \%$ & 0 & 0 & 4 & 6 & 2 & 1 & 0 & 1 & 1 & 0 & 0 & 0 & $0.5255 \mathrm{ab}$ \\
\hline GE $10 \%$ & 0 & 0 & 5 & 4 & 1 & 2 & 0 & 0 & 1 & 1 & 0 & 0 & $0.4920 a b$ \\
\hline $\mathrm{GE} 5 \%+\mathrm{MO} 2 \%$ & 0 & 0 & 4 & 4 & 2 & 2 & 1 & 0 & 1 & 0 & 0 & 0 & $0.4785 a b$ \\
\hline SOE $10 \%$ + MO $2 \%$ & 0 & 0 & 3 & 3 & 4 & 1 & 1 & 1 & 1 & 0 & 0 & 0 & $0.4431 a b$ \\
\hline GE 5\% & 0 & 0 & 3 & 3 & 4 & 2 & 0 & 0 & 0 & 0 & 1 & 0 & $0.4255 \mathrm{ab}$ \\
\hline GE $15 \%$ & 0 & 0 & 4 & 3 & 2 & 0 & 2 & 0 & 1 & 0 & 0 & 0 & $0.4147 \mathrm{ab}$ \\
\hline No application & 0 & 0 & 3 & 3 & 3 & 1 & 1 & 0 & 0 & 0 & 0 & 1 & $0.3938 a b$ \\
\hline SOE $10 \%$ & 0 & 0 & 3 & 3 & 2 & 1 & 0 & 2 & 0 & 0 & 0 & 0 & $0.3684 a b$ \\
\hline GE $15 \%+$ MO $2 \%$ & 0 & 0 & 2 & 3 & 3 & 0 & 1 & 0 & 0 & 0 & 0 & 0 & $0.3105 b$ \\
\hline
\end{tabular}

*Averages followed by different letters in the columns differ by the Tukey's test at $5 \%$ significance.

According to Faust et al. (1997), the best scenario to make a rest-breaking agent work is its application when two thirds of the cold requirement of a plant has been met, in order to reach good and uniform budbreak. Accumulation of cold in the whole winter in 2017 was lower than the period of two thirds of cold hours cited by Faust et al. (1997) as the ideal moment for the application of rest-breaking agents.

In 2017, when accumulation of cold was low, treatments that exhibited the best results were also identified. The treatment with GE $10 \%+$ MO $2 \%$ was the one that exhibited the highest FBR and the lowest ABT, although it did not differ statistically from the other treatments.

Efficiency of a certain concentration of a rest-breaking agent may vary, depending on the species and the cultivar. However, Botelho and Müller (2007) tested different rest-breaking agents in apple trees of the cultivar Fuji Kiku and observed that the treatment with GE $10 \%+\mathrm{MO} 2 \%$ was one of the treatments that exhibited the best results in their study, similar to the ones shown by hydrogenated cyanamide. Carvalho et al. (2016) also observed that the concentration of $10 \%$ garlic extract is a good one to induce sprouting in vines, due to the excellent results found. These data corroborate with the results found and reported in this paper, i.e., GE 10\% + MO 2\% exhibited better results than the other rest-breaking agents at different concentrations in distinct years.

In both years, concentrations with the best performance kept constant; besides GE 10\% + MO 2\%, treatments MO 2\% and GE $10 \%$ were promising, since they had satisfactory results, even though there were some differences between both years under study. According to Marchi et al. (2017), application of mineral oil is efficient to overcome dormancy because, when the product covers the buds, it deprives them of oxygen and triggers the so-called Pasteur effect. It leads to the production of ethanol, which is a substance (alcohol) that induces the bud to leave the dormancy stage.

The active ingredient present in garlic that induces budding in buds has not been well defined yet. According to OrrantiaAraujo et al. (2019), garlic extract is rich in diallyl disulphide and other sulfur compounds. These, when applied to the bud, cause an increase in $\mathrm{H}_{2} \mathrm{O}_{2}$ levels, inducing oxidative stress and subsequently budding sprouting. There is also another theory, described by Perussi et al. (2010), where garlic contains allyl alcohol, which converts into a toxic aldehyde when it undergoes oxidation by the enzyme alcohol dehydrogenase, destroys glutathione and, consequently, increases $\mathrm{H}_{2} \mathrm{O}_{2}$ levels. This process triggers many metabolic changes and does not keep buds in the dormancy stage. Regardless of the active principle present in garlic which is responsible for the sprouting induction, it was clear in the present and previous researches that the application of garlic extract causes changes in the bud metabolism, inducing them to sprout and leaving the dormancy stage.

Researchers have been suggesting bud-inducing garlic extract for temperate fruit in mild winter regions. Abou-Zaid and Badawy (2018) suggest garlic extract as a product to be used in overcoming vines dormancy in Egypt, because the product has an 
efficiency similar to hydrogenated cyanamide and also lower environmental impact and acquisition cost. Ímrak et al. (2016) indicate garlic extract in the induction of apple sprouting in Turkey, since this product showed good results in sprouting induction, and the commercialization of hydrogen cyanamide is prohibited in Turkey due to its high toxicity. The use of alternative rest-breaking agents in order to overcome dormancy of buds of kiwifruit vines in conditions of mild winter is efficient, but the efficiency of a certain agent depends much on the accumulation of hibernal cold. The combination of different concentrations of garlic extract, either associated with mineral oil or nor, is one of the main alternatives to induce budbreak in kiwifruit vines grown in an organic system in conditions of mild winter.

\section{CONCLUSION}

Garlic extract at $10 \%+$ mineral oil at $2 \%$ was the most efficient rest-breaking agent that induced budbreak in both production cycles under evaluation, due to the stability of its results in years when there was different accumulation of hibernal cold. Thus, this dose is recommended for budbreak induction in kiwifruit vines grown in an organic system.

Concentrations close to GE 15\%, associated with MO 2\%, cause phytotoxicity to buds of 'Bruno' kiwifruit vines.

\section{ACKNOWLEDGMENTS}

The authors would like to thank the Capes for granting scholarships and the Embrapa Clima Temperado for providing climatic data.

\section{AUTHOR'S CONTRIBUTION}

Conceptualization, Martins C. R. and Mello-Farias P.; Methodology, Santos R. F. and Martins C. R; Investigation, Santos R. F and Mello-Farias P.; Writing - Original Draft, Santos R. F., Marques L. O. D. and Konzen L. H.; Writing - Review and Editing, Santos R. F., Marques L. O. D., Konzen L. H. and Carvalho I. R.; Funding Acquisition, Martins C. R., Malgarim M. B. and Mello-Farias P; Supervision, Mello-Farias P.

\section{REFERENCES}

Abou-Zaid, E. A. A. and Badawy, E, F. M. (2018). Improvement the production of red roomy grapevines under warm climatic conditions. Assiut Journal of Agricultural Sciences, 49, 98-108. https://doi.org/10.21608/ajas.2018.28276

Botelho, R. V. and Müller, M. M. L. (2007). Extrato de alho como alternativa na quebra de dormência de gemas em macieiras cv. Fuji Kiku. Revista Brasileira de Fruticultura, 29, 37-41. https://doi.org/10.1590/S0100-29452007000100010

Carvalho, J. N., Pereira, L. S., Carvalho, P. A. and Decarlos Neto, A. (2016). Application of natural garlic extract to overcome bud dormancy of grapevines 'BRS Rúbea' and 'BRS Cora'. Australian Journal of Crop Science, 10, 216-219.

Carvalho, R. I. N. and Biasi, L. A. (2012). Índice para avaliação da intensidade de dormência de gemas de fruteiras de clima temperado. Revista Brasileira de Fruticultura, 34, 936-940. https://doi.org/10.1590/S0100-29452012000300037

Carvalho, R. I. N. and Silva, E. Q. (2010). Dormancy index of apple tree buds measured by the single node cutting biological test. Acta Horticulturae, 872, 101-105. https://doi.org/10.17660/ActaHortic.2010.872.11

Champagnat, P. (1983). Bud dormancy, correlation between organs, and morphogenesis in Woody plants. Soviet Plant Physiology, 30, $458-471$. 
Citadin, I., Raseira, M. C. B., Herter, F. G. and Silveira, C. A. P. (2002). Avaliação da necessidade de frio em pessegueiro. Revista Brasileira de Fruticultura, 24, 703-706. https://doi.org/10.1590/S0100-29452002000300034

El Yaacoubi, A., Malagi, G., Oukabli, A., Citadin, I., Hafidi, M., Bonhomme, M. and Legave, J-M. (2016). Differentiated dynamics of bud dormancy and growth in temperate fruit trees relating to bud phenology adaptation, the case of apple and almond trees. International Journal of Biometeorology, 60, 1695-1710. https://doi.org/10.1007/s00484-016-1160-9

Faust, M., Erez, A., Rowland, L. J., Wang, S. Y. and Norman, H. A. (1997). Bud dormancy in perennial fruit trees: Physiological basis for dormancy induction, maintenance, and release. American Society for Horticultural Science, 32, 623-629. https://doi.org/10.21273/ HORTSCI.32.4.623

Hawerroth, F. J., Herter, F. G., Petri, J. L., Leite, G. B. and Pereira, J. F. M. (2010). Dormência em frutíferas de clima temperado (Documento 310). Pelotas (SP): Embrapa Clima Temperado. [Accessed Aug. 20, 2018]. Available at: https://www.embrapa.br/clima-temperado/ busca-de-publicacoes/-/publicacao/884602/dormencia-em-frutiferas-de-clima-temperado

Hoeberichts, F. A., Povero, G., Ibañez, M., Strijker, A., Pezzolato, D., Mills, R. and Piaggesi, A. (2017). Next generation sequencing to characterise the breaking of bud dormancy using a natural biostimulant in kiwifruit (Actinidia deliciosa). Scientia Horticulturae, 225, 252-263. https://doi.org/10.1016/j.scienta.2017.07.011

Ímrak, B., Küden, A. B., Küden, A., Sarıer, K. and Çimen, B. (2016). Chemical application affected dormancy breaking in 'Modi' apple cultivar under subtropical conditions. Acta Scientiarum Polonorum Hortorum Cultus, 15, 265-277.

Leonel, S., Tecchio, M. A. and Cóser, G. M. A. G. (2015). Dormancy breaking of the fig tree with hydrogen cyanamide and garlic extrate. British Journal of Applied Science and Technology, 10, 1-10. https://doi.org/10.9734/BJAST/2015/18194

Marchi, T., Oliari, I. R. C., Maia, A. J., Sato, A. J. and Botelho, R. V. (2017). Indução da brotação de gemas de macieiras com aplicação de óleos vegetais e mineral. Revista Ciência Agronômica, 48, 501-512.

Orrantia-Araujo, M. A., Martínez-Téllez, M. A., Corrales-Maldonado, C., Rivera-Domínguez, M. and Vargas-Arispuro, I. (2019). Changes in glutathione and glutathione disulfide content in dormant grapevine buds treated with garlic compound mix to break dormancy. Scientia Horticulturae, 246, 407-410. https://doi.org/10.1016/j.scienta.2018.10.064

Perussi, G. P. G., Botelho, R. V., Ricklli, E. and Pavanello, A. P. (2010). Break of dormancy of 'Fuji Kiku' apple trees with garlic extract. Semina: Ciências Agrárias, 31, 313-320. https://doi.org/10.5433/1679-0359.2010v31n2p313

RStudio Team. (2016). Integrated Development. Boston: RStudio. [Accessed Aug. 30, 2018]. Available at: http://www.rstudio.com/

Salinero, M. C., Vela, P. and Sainz, M. J. (2009). Phenological growth stages of kiwifruit (Actinidia deliciosa 'Hayward'). Scientia Horticulturae, 121, 27-31. https://doi.org/10.1016/j.scienta.2009.01.013

Silveira, S. V., Anzanello, R., Simonetto, P. R., Gava, R., Garrido, L. R., Santos, R. S. S. and Girardi, C. L. (2012). Aspectos Técnicos da Produção do Quivi (Documento 79). Bento Gonçalves: Embrapa Uva e Vinho. [Accessed Aug. 13, 2018]. Available at: https://www. infoteca.cnptia.embrapa.br/bitstream/doc/662824/1/doc079.pdf

Soquetta, M. B., Stefanello, F. S., Huerta, K. M., Monteiro, S. S., Rosa, C. S. and Terra, N. N. (2016). Characterization of physiochemical and microbiological properties, and bioactive compounds, of flour made from the skin and bagasse of kiwi fruit (Actinidia deliciosa). Food Chemistry, 199, 471-478. https://doi.org/10.1016/j.foodchem.2015.12.022

Weinberger, J. H. (1950). Chilling requirements of peach varieties. Proceedings of the American Society for Horticultural Science, 56, $122-128$. 